\title{
MAXIMAL VALUES OF SYMMETRIC FUNCTIONS IN DISTANCES BETWEEN POINTS
}

\author{
ARTüRAS DUBICKAS
}

Abstract. In this note we find the maximal values of several symmetric functions in the variables which are the squares of distances $\left|z_{i}-z_{j}\right|^{2}, 1 \leqslant i<j \leqslant d$, between some $d$ complex points $z_{1}, \ldots, z_{d}$ in the unit disc. We compute the maximums of $\sigma_{m}$, for $m=1,2,3,4$, explicitly and find the conditions on $z_{1}, \ldots, z_{d}$ under which those maximal values are attained. This problem is motivated by an inequality of Cassels (1966) and a subsequent conjecture of Alexander.

Mathematics subject classification (2010): 52A40, 11R06.

Keywords and phrases: Unit circle, extremal configuration of points, maximal sums of distances.

\section{REFERENCES}

[1] R. Alexander, On an inequality of J. W. S. Cassels, Amer. Math. Monthly, 79, (1972), 883-884.

[2] R. AleXAnder, On the sum of distances between n points on a sphere, Acta Math. Acad. Sci. Hung., 23, (1972), 443-448.

[3] G. Ambrus, K. M. Ball and T. ErdéLyi, Chebyshev constants for the unit circle, Bull. Lond. Math. Soc., 45, (2013), 236-248.

[4] J. S. BRAuChart AND P. J. GRABner, Distributing many points on spheres: minimal energy and designs, J. Complexity, 31, (2015), 293-326.

[5] J. W. S. CAssels, On a problem of Schinzel and Zassenhaus, J. Math. Sciences, 1, (1966), 1-8.

[6] A. DuBickas, The maximal conjugate of a non-reciprocal algebraic integer, Lith. Math. J., 37, (1997), 129-133.

[7] A. DuBickAS, On the measure of a nonreciprocal algebraic number, Ramanujan J., 4, (2000), 291 298.

[8] L. Fejes Tóth, On the sum of distances determined by a pointset, Acta Math. Acad. Sci. Hung., 7, (1956), 397-401.

[9] E. HoRvat, The sum of a power of distances, Ann. Univ. Sci. Budapest. Eötvös Sect. Math., 17, (1975), 125-129.

[10] X. Hou AND J. Shao, Spherical distribution of 5 points with maximal distance sum, Discrete Comput. Geom., 46, (2011), 156-174.

[11] N. Nikolov And R. Rafailov, On the sum of powered distances to certain sets of points on the circle, Pacific J. Math., 253, (2011), 157-168.

[12] N. NiKOLOV AND R. RAFAILOV, On extremums of sums of powered distances to a finite set of points, Geom. Dedicata, 167, (2013), 69-89.

[13] V. V. Prasolov, Polynomials, Algorithms and Computation in Mathematics 11, 2nd. ed., SpringerVerlag, Berlin, 2010.

[14] I. SCHUR, Über die Verteilung der Wurzeln bei gewissen algebraischen Gleichungen mit ganzzahligen Koeffizienten, Math. Z., 1, (1918), 377-402.

[15] K. Stolarsky, The sum of the distances to certain pointsets on the unit circle, Pac. J. Math., 59, (1975), 241-251. 